\title{
A label-free mass spectrometry method for the quantification of protein isotypes
}

\author{
Robert D. Winefield ${ }^{a}$, Todd D. Williams ${ }^{b}$, and Richard H. Himes ${ }^{a},{ }^{*}$ \\ aDepartment of Molecular Biosciences, University of Kansas, Lawrence, KS 66045, USA \\ bMass Spectrometry Laboratory, University of Kansas, Lawrence, KS 66045, USA
}

\section{Abstract}

\begin{abstract}
Successful quantitative mass spectrometry (MS) requires strategies to link the mass spectrometer response to the analyte abundance, with the response being dependent on more factors than just analyte abundance. Label-dependent strategies rely on the incorporation of an isotopically labeled internal standard into the sample. Current label-free strategies (performed without internal standards) are useful for analyzing samples that are unsuitable for isotopic labeling but are less accurate. Here we describe a label-free technique applicable to analysis of products from related genes (isotypes). This approach enables the invariant tryptic peptide sequences within the family to serve as "built-in" internal standards and the isotype-specific peptide sequences to report the amount of the various isotypes. A process of elimination segregates reliably trypsin-released standard and reporter peptides from unreliably released peptides. The specific MS response factors for these reporter and standard peptides can be determined using synthetic peptides. Analysis of HeLa tubulin digests revealed peptides from $\beta \mathrm{I}-, \beta \mathrm{II}-, \beta \mathrm{III}-, \beta \mathrm{IVb}-$, and $\beta \mathrm{V}$-tubulin, eight of which were suitable; along with five standard peptides for quantification of the $\beta$-tubulin isotypes. To show the utility of this method, we determined that $\beta$ I-tubulin represented $77 \%$ and $\beta$ IIItubulin represented $3.2 \%$ of the total HeLa $\beta$-tubulin.
\end{abstract}

\section{Keywords}

Label-free quantification; Mass spectrometry; Targeted proteomic analysis; Tubulin isotype quantification; Tubulin

\begin{abstract}
During recent years, mass spectrometry (MS) ${ }^{1}$ has become the preferred technique to resolve and quantify gene products in crude cellular extracts—an endeavor more commonly referred to as proteomics. The reason is that the modern liquid chromatography (LC)-MS device delivers unparalleled sensitivity, specificity, and resolving power in addition to being easily adapted for high-throughput analysis [1]. Although LC-MS excels at detecting and identifying an analyte, a task it is capable of performing in a single experiment using tandem mass spectrometry (MS/MS), quantification is more challenging. This is reflected by the profusion of quantitative mass spectrometry (QMS) techniques currently in use (reviewed in Refs. [1-3]). Most protein QMS techniques share a common work flow in which the intact purified protein or extract is digested proteolytically or chemically and the resulting peptide
\end{abstract}

\footnotetext{
(C) 2009 Elsevier Inc. All rights reserved.

*Corresponding author. Fax: +1 785864 5321. himes@ku.edu (R.H. Himes).

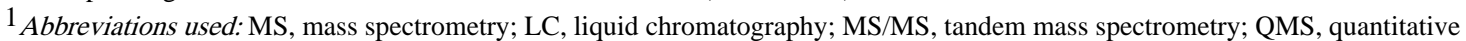
mass spectrometry; XIC, extracted ion chromatogram; FWHM, full-width half-maximum; IUPAC, International Union of Pure and Applied Chemistry; SD, standard deviation; CV, coefficient of variation; MALDI, matrix-assisted laser desorption/ionization; TOF, time-of-flight.
} 
mixture is resolved by LC. Then it is analyzed by an electrospray ionizing mass spectrometer coupled directly to the LC device [1]. The difference in the techniques lies in the unique way in which they overcome the intrinsic limitations of quantification by MS. These limitations stem from the fact that the response of the MS detector is dependent on more factors than just analyte abundance. The additional factors include the nature of the sample, the matrix, and both the chromatographic and ionization conditions [1]. Because proteolytic peptides display a wide range of physicochemical properties, peptide ion LC-MS molar response factors can vary over two orders of magnitude. This necessitates that a calibration or comparison strategy be implemented to link the LC-MS response to the abundance of each peptide. The various QMS techniques can be categorized based on whether the method of comparison or calibration is dependent on the addition of isotopic labels (label dependent) or not (label free).

Label-dependent QMS techniques employ differential labeling to add inert (stable isotopic) mass tags to every protein in the sample. The peptides derived from these proteins then function as a "built-in" internal standard. The labeled and unlabeled samples are combined prior to digestion and MS analysis, ensuring that the digestion, chromatographic, and ionization conditions are identical for both the internal standard and the analyte. For this reason, label-dependent QMS techniques are considered to be the most precise and accurate of the QMS techniques [4-11].

Label-free techniques compare the quantitative data from multiple LC-MS analyses performed without incorporating an isotopic label into the samples [1,3]. Robust quantification by label-free techniques requires more MS injections per sample to build a dataset large enough to permit valid statistical analysis. The additional statistical analysis is required to correct for systematic error in each experiment $[1,12,13]$. Label-free QMS is preferred in situations where incorporating isotopic labels prior to proteolytic digestion is made impractical or even impossible by difficulties in obtaining enough material from which to extract sufficient protein for analysis. Although post-digest labeling techniques exist, using them introduces additional sources of random sample variation and any incremental increase in accuracy over label-free QMS might not justify the extra effort, expense, and complication of reliably incorporating isotopic labels into the sample.

In the context of a targeted analysis of a proteome, there is a niche where a label-free QMS technique is the most sensible approach, namely quantifying the products from related genes (isotypes). Protein families applicable to such examination include cytochrome P450 isozymes, kinesins, dyneins, chaperones (e.g., the Hsp70 family), and tubulin. A feature of these gene product families is the opportunity to use the invariant amino acid sequences within the families as built-in internal standards and to use the isotype-specific portions of the sequence to report the amount of the various isotypes. We present tubulin as an archetype of this approach.

Humans express seven $\beta$-tubulin protein isotypes ( $\beta \mathrm{I}, \beta \mathrm{II}, \beta \mathrm{III}, \beta \mathrm{IVa}, \beta \mathrm{IVb}, \beta \mathrm{V}$, and $\beta \mathrm{VI}$ ) with very similar protein sequences, with the principal source of sequence divergence residing in the final $20 \mathrm{C}$-terminal residues [14-16]. Tubulin is the subject of intensive investigation because changes in the expression pattern of $\beta$-tubulin isotypes have been implicated in drug-resistant malignancies. For this reason, attempts have been made to determine the expression patterns of $\beta$-tubulin isotypes in a number of cell lines and tissues. A sensitive generalized approach to isotype quantification of tubulin would significantly improve the ability to determine the role of tubulin in cell biology and possibly human disease intervention. 
Quantification of isotypes within a single family of proteins relies on the fact that the abundance of unique tryptic peptides will reflect the abundance of the parent protein $[17,18]$. This statement is predicated on the observation that every member of the protein family is essentially an identical substrate of trypsin. For example, it has long been established that members of both the human a and $\beta$-tubulin families are highly homologous, overall, in terms of both sequence and tertiary structure [19]. Thus, the abundance of those reliably released tryptic peptides that are ubiquitous to every member of either the $\alpha$ - or $\beta$-tubulin family (standard peptides) should reflect the total concentration of $\alpha$ - and $\beta$-tubulin in the sample. Furthermore, because $\alpha$ - and $\beta$-tubulin are present in a 1:1 molar ratio within microtubules [19], the abundance of standard peptides from either $\alpha$ - or $\beta$-tubulin will reflect the concentration of both $\alpha$ - and $\beta$-tubulin within the sample.

Our label-free method for quantifying tubulin isotypes encompassed three phases. First, we identified potential standard and reporter peptides present in tryptic digests of purified $\mathrm{HeLa}$ tubulin. Second, we identified the reliably released peptides within this subset to ensure that the abundance of reporter and standard peptides always reflects the abundance of the parent protein(s). We define standard peptides as reliably released tryptic peptides common to all protein isotypes found in the sample. Reporter peptides are reliably released tryptic peptides that are unique to a particular isotype. Finally, we determined the peptide-specific LC-MS response factors for a selection of these reporter and standard peptides. In so doing, we were able to derive an absolute estimate of the abundance of $\beta I$ - and $\beta$ III-tubulin in HeLa cells.

\section{Materials and methods}

\section{General materials and protocols}

HeLa tubulin was a kind gift from Mary Ann Jordan (University of California, Santa Barbara). Saccharomyces cerevisiae strain AD1-8 [20] tubulin was purified as described previously [21,22]. Protein concentration was determined using the Bradford assay [23].

\section{Tubulin digests}

Sequencing-grade trypsin (Promega, Madison, WI, USA) was used for all digestions. All tryptic digestions were carried out at $37^{\circ} \mathrm{C}$ for $16-20 \mathrm{~h}$. BioSpin 6 columns (Bio-Rad, Hercules, CA, USA) were used to exchange the buffers in the protein solutions to 50 $\mathrm{mMNH}_{4} \mathrm{HCO}_{3}(\mathrm{pH} 7.8)$ prior to proteolysis. HeLa tubulin was digested in a $50-\mu \mathrm{l}$ solution consisting of $0.25 \mu \mathrm{g} / \mu \mathrm{l}$ tubulin and $12.5 \mathrm{ng} / \mu \mathrm{l}$ trypsin in $50 \mathrm{mM} \mathrm{NH}_{4} \mathrm{HCO}_{3}(\mathrm{pH} 7.8) . S$. cerevisiae tubulin was digested in a $25-\mu \mathrm{l}$ solution consisting of $1.0 \mu \mathrm{g} / \mu \mathrm{l}$ tubulin and 62.5 $\mathrm{ng} / \mu \mathrm{l}$ trypsin in $50 \mathrm{mM} \mathrm{NH}_{4} \mathrm{HCO}_{3}$, into which was added 2-8 $\mu$ l of the synthetic peptide solution (see below). The $S$. cerevisiae tubulin was digested to produce a matrix, into which the synthetic peptides could be placed, that would approximate that found in HeLa tubulin digests without interfering with the quantification of the synthetic peptides.

\section{Peptide nomenclature}

In this study, reporter peptides are assigned an alphanumeric code that reflects their parent isotype. BI- $n$ denotes a reporter peptide for $\beta$ I-tubulin (the numerals are assigned randomly), BII- $n$ denotes the $n$th reporter peptide for $\beta$ II-tubulin, and so on. Standard peptides are defined as tryptic peptides that are present in, and reliably released from, every protein isotype within a family, a property that enables them to be used as an internal standard for quantification. In this context, the standard peptides originate from either a-tubulin or $\beta$ tubulin. Standard peptides from $\alpha$-tubulin were designated as AA- $n$ to denote their presence in all a-tubulin isotypes (i.e., "all alpha"). Likewise standard peptides from $\beta$-tubulin were designated AB- $n$. 


\section{Synthetic peptide solutions}

Two of the standard peptides (AA-3, EDMAALEK, 906.02 Da, and AB-1, FPGQLNADLR, 1130.27 Da) and two of the reporter peptides (BI-1, ALTVPELTQQVFDAK, 1659.90 Da, and BIII-3, LATPTYGDLNH LVSATMSGVTTSLR, 2605.95 Da) were selected for synthesis for the purpose of determining the unique LC-MS response factor for each. Synthesis was performed by GeneScript (Scotch Plains, NJ, USA). An aqueous mixture of these synthetic peptides (100 $\mu \mathrm{MAA}-3,100 \mu \mathrm{M}$ AB-1, $80 \mu \mathrm{M}$ BI-1, and $13 \mu \mathrm{M}$ BIII-3 in deionized water) was prepared prior to use. The molar ratio of peptides reflects the relative concentration of the $\beta I$ isotype as determined by Newton and coworkers, with sufficient BIII-3 being added to ensure a suitable signal [24].

\section{Capillary HPLC mass spectroscopic analysis of tryptic digests}

The presence of the reporter peptides in each digest was confirmed by MS/MS experiments performed contemporaneously with quantitative LC-MS injections. Following tryptic digestion, samples were diluted either 5- or 20 -fold in $50 \mathrm{mM} \mathrm{NH}_{4} \mathrm{HCO}_{3}(\mathrm{pH} 7.8$ ), and $5 \mu \mathrm{l}$ was injected into a Zorbax C18 column $(300 \mu \mathrm{M} \times 5 \mathrm{~cm}, 5 \mu \mathrm{Mparticle} \mathrm{size,} 300 \AA$ A pore size, MicroTech Scientific, Vista, CA, USA). The peptides were eluted with a linear gradient from $1 \%$ to $94 \% \mathrm{CH}_{3} \mathrm{CN}, 0.08 \%$ formic acid, over $70 \mathrm{~min}$. Total column effluent $(6 \mu \mathrm{l} / \mathrm{min})$ was connected to an LTQ-FT hybrid mass spectrometer (Thermo Scientific, Bremen, Germany) operated in one of two modes. For MS/MS experiments, the data were obtained from a full-scan MS survey in FT mode $\left(25,000\right.$ resolution and fill target of $\left.1 \times 10^{5}\right)$. The three most abundant ions in the survey were fragmented in the linear ion trap for a fill to $5 \times$ $10^{3}$ or $200 \mathrm{~ms}$, and the ions were excluded from reanalysis for $30 \mathrm{~s}$. Spectra used for quantification were acquired in FT full-scan mode at 50,000 resolution, 3 micro scans, and a fill target of $1 \times 10^{5}$ or 1000 ms maximum fill time.

\section{Spectrum processing and collection of XIC data}

The LC-MS spectra were processed by hand. The identity of all peptides investigated was confirmed by MS/MS performed on one of the 18 digests that comprised this study, and thereafter the identity was established based on the observed $\mathrm{m} / \mathrm{z}$ ratio. Extracted ion chromatograms (XICs) specific to the monoisotopic peptide ion were obtained using Xcalibur software (Thermo Scientific, Waltham, MA, USA). For all ions, the XIC parameters were the $\mathrm{m} / \mathrm{z}$ ratio of the monoisotopic ion plus/minus the full-width halfmaximum (FWHM) of the $\mathrm{m} / \mathrm{z}$ signal. The area of this XIC peak (hereafter referred to as the LC-MS signal) was determined by integration using Xcalibur software. For peaks with poor peak shape, the integration parameters were restricted to maintain a constant peak width at half height on the LC peaks. Limits of detection and quantitation were calculated (in accordance with International Union of Pure and Applied Chemistry (IUPAC) guidelines [25]) using intensity of the strongest $\mathrm{m} / \mathrm{z}$ signal in the XIC that was unassociated with an ion cluster. It was necessary to calculate the limits for each peptide individually due to background signal variation across the chromatographic spectrum.

\section{Protein quantification}

Peptide signal response factors (signal/mole peptide injected) in LC-MS can vary by sequence and daily instrument conditions. To compare signals across samples, multiple injections, and different days requires normalization of signals to some in-sample internal standard. Depending on the experiment, one of three normalization strategies was applied in this work. When assessing the experimental error intrinsic to the LC-MS system, raw LCMS data were used to construct a pairwise comparison table composed of ratios of the LCMS signal for every pair of identifiable peptides detected in a single injection. "Identifiable" was taken to mean an exact mass corresponding to a tubulin tryptic fragment. For each 
digest, the mean and standard deviation (SD) of the ratios for each peptide pair were calculated using the ratios collected from triplicateLC-MS injections of each digest. The coefficient of variation (CV) of the ratios for all ratio data obtained from the digest were averaged to establish the baseline level of signal variance (the mean CV for all peptide pairs in that injection) for the LC-MS system independent of trypsin activity.

This procedure was modified to judge the reliability of the peptide's release. The SD and mean CV of ratios (across all digests) for each peptide pair were calculated. By trial and error, data derived from a single peptide were omitted from the calculated ratios and the $\mathrm{CV}$ statistics across all digests were recalculated. Peptides that trypsin releases unreliably skew the mean CV and inflate the SD. Recalculating the CV statistics without unreliable ratio data derived from them will systematically reduce the SD while simultaneously lowering the mean $\mathrm{CV}$. When the subset of peptides has been reduced to the point where the recalculated mean $\mathrm{CV}$ is less than or equal to the recalculated baseline value, the analysis is complete. Peptides deemed to be unreliable by this method were excluded from further analysis.

\section{Results \\ Selecting reporter ions}

Alignment and virtual digest analysis, conducted on the known sequences of every isotype in the tubulin family, is an essential first step in the task of identifying standard and reporter peptides because these will form a limited subset of the tryptic peptides present in the digest. Three criteria were applied to the selection of appropriate standard and reporter peptides. Any peptides that did not meet all three criteria were discarded. First, the peptide ions had a distinct and easily identifiable LC-MS signal (e.g., an uninterrupted ion cluster with a mass spectrum signal at least 10 times higher than the limit of quantitation) so as to facilitate accurate quantification across multiple digests. Second, the identity of these peptide ions was confirmed first by MS/MS and thereafter by inspection of the peptide's $m / z$ ratio. The resolution and mass accuracy of the LTQ-FT hybrid mass spectrometer $(<5 \mathrm{ppm})$ enabled us to identify our standard and reporter peptides in this manner based solely on their $\mathrm{m} / \mathrm{z}$ ratio without further MS/MS experiments. Third, the precision and accuracy of measurement by this method are limited not just by precision and accuracy of the LC-MS device but also by the reliability of tryptic release. We define reliably released peptides as those whose observed abundance, relative to other peptides, does not vary between identical tryptic digests. In essence, this means selecting peptides with the least dispersion in LC-MS signals between digests.

Logically, the ratio of the respective abundances for two reliably released peptides will remain unchanged between independent but equivalent digests. This entails examining the magnitude of data dispersion observed across many injections or digests. Note that the CV, a normalized measure of dispersion, is used in lieu of the SD to permit the analysis of ratios from any combination of peptides, enabling the averaging of all ratios (all peptide combinations) observed in a single LC-MS injection. The mean CV of peptide ratios (independent of trypsin activity) in three LC-MS injections from a single digest was $26 \%$. Unreliable peptides can then be identified by trial and error if the CV statistics from multiple independent digests for ratios comprising a common peptide are compiled and then recalculated after excluding ratios of a particular peptide pairing. If the second peptide in that pair was unreliably released, the mean $\mathrm{CV}$ of the remaining ratios should decrease in every instance where the abundance of the unreliable peptide is compared with another. The process is complete when the adjusted mean CV for the remaining peptides is less than or equal to $26 \%$, the variance observed independent of trypsin activity. The effects of these analyses are illustrated with box and whisker plots that display range, mean, and interquartile statistics (Fig. 1). When the modified data are plotted, it is apparent that the 
excluded peptides have contributed to the exaggerated dispersion and elevated mean CV seen in the plots of unmodified data.

MS/MS experiments had identified 9 tryptic peptides with the potential to be used as standards in this analysis and an additional 15 peptides unique to particular isotypes of $\beta$ tubulin. Tryptic peptides from six $\beta$-tubulin isotypes ( $\beta$ I, $\beta$ II, $\beta$ III, $\beta$ IVa, $\beta$ Ivb, and $\beta$ V) were detected (Table 1). This is the first time that $\beta$ IVa and $\beta$ V have been detected in $\mathrm{HeLa}$ tubulin. Applying the strategy described above to data from three independent digests, 5 of the 9 potential standard peptides and 8 of the 15 potential reporter peptides were shown to be reliably released (Table 1 ).

\section{Peptide-specific LC-MS response factors}

We determined the LC-MS response factors for two standard peptides (AA-3 and AB-1) and two reporter peptides (BI- 1 and BIII-3) that could be used to quantify the $\beta 1$ and $\beta I I I$ isotypes. The peptides were synthesized and a mixture of all four synthetic peptides was added, in increasing concentration, to samples of purified $S$. cerevisiae tubulin prior to digestion with trypsin. The yeast tubulin digest provides a sample matrix that mimics the matrix found in digests of HeLa tubulin without interfering with the quantification of the synthetic peptides; the synthetic peptides being measured are absent from the two a-tubulin proteins and one $\beta$-tubulin protein produced by $S$. cerevisiae. The peptides were quantified, in quintuplicate, at four concentrations for a total of 20 independent digests and LC-MS injections. Reliably released tryptic peptides from $S$. cerevisiae tubulin were used as internal standards to normalize the data from each experiment prior to determining the response factors (Table 2) for each synthetic peptide using linear regression analysis (Fig 2).

\section{Quantitative analysis}

A total of 15 replicate tryptic digests of HeLa tubulin were prepared and injected over a 96-h period. A typical ion chromatogram for these LC-MS injections is shown in Fig. 3. Quantitative data were obtained from XICs from each digest and analyzed manually. Reporter peptide data were normalized to help mitigate error; the correction factor for each digest was derived by considering the relative LC-MS response of all six standard peptides. The mean LC-MS signals for the four peptides for which response factors were determined after normalization are presented in Table 3 . The concentration of each of these peptides was calculated by dividing the mean LC-MS signal for a peptide (and obtained from a known volume of sample) by the appropriate response factor (Table 2). Using the mean absolute abundance of AA-3 and AB- 1 standards, a figure of $2.54 \mathrm{pmol} / \mu \mathrm{l}$ for total tubulin was computed. The Bradford protein assay obtained independently of the LC-MS results showed that the total concentration of $\beta$-tubulin in the digests was $2.5 \mathrm{pmol} / \mu \mathrm{l}$ (data not shown).

\section{Discussion}

We have described a method by which the sensitivity and selectivity of modernLC-MS techniques may be applied to the quantification of closely related proteins or the comparison of separate samples without the need for isotopic labeling or the addition of internal standards to samples. The method is simple, specific, and sensitive. The QMS method described here has the advantage of not requiring the manipulations required to introduce isotopically labeled peptides. As with label-dependent QMS methods, this method permits the accurate comparison of dissimilar samples because a built-in peptide-based internal standard is available to calibrate the LC-MS signals from each sample. We envision this technique being useful to laboratories seeking a simple, accurate, and sensitive technique to determine the abundance of proteins with homologous sequences such as isotypes or mutated forms of a particular protein and proteins that are closely related. The fundamental 
perquisite, or possible limitation, of this strategy is implied in this work and in a related quantification of cytochrome 450 isozymes by matrix-assisted laser desorption/ionization (MALDI) [26]. A protein family must be enriched to the point were the isotype reporter peptide of least abundance is detectable. The standard and reporter peptides for tubulin in the current work and the reporter peptides in the P450 work [26] will be reliable for all MS methods, but the specific sensitivity and application to a given sample is driven by the sample preparation and available instrumentation.

We applied this technique to HeLa tubulin and were able to detect $\beta I I, \beta I V a$, and $\beta$ V-tubulin in HeLa tubulin for the first time. Moreover, we easily detected the $\beta$ III isotype and were able to quantify its concentration. Previous studies, using immunostaining, failed to detect $\beta$ III-tubulin in purified HeLa tubulin [24] or HeLa cell extracts [27] except by overloading the gels [24]. Accurate measurements of analyte abundance using antibodies are complicated by significant variations in the reactivity shown by individual antibodies for their targets $[28,29]$. Verdier-Pinard and coworkers did detect $\beta$ III-tubulin in HeLa tubulin when they examined undigested HeLa tubulin samples by LC-MS [30] but were unable to detect the C-terminal peptide of the $\beta \mathrm{III}$ isotype when they examined $\mathrm{CNBr}$ digests of $\mathrm{HeLa}$ tubulin using MALDI-time-of-flight (TOF). In addition, they were unable to detect $\beta$ II-,

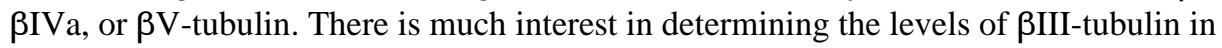
mammalian cells as mounting clinical evidence demonstrates a correlation between increased expression of this normally neuronal specific isotype and resistance to chemotherapeutic agents [31-39]. Investigations in this field require quantitative techniques that are able to detect perturbations in the natural abundance of all isotypes, and we believe that the technique described here is ideally suited for this.

\section{Acknowledgments}

We thank Mary Ann Jordan for her kind gift of purified HeLa tubulin and Melinda L. Toumi for her helpful suggestions during the preparation of this manuscript. This work was supported by National Institutes of Health (NIH) Grant CA 105305.

\section{References}

1. Bantscheff M, Schirle M, Sweetman G, Rick J, Kuster B. Quantitative mass spectrometry in proteomics: a critical review. Anal. Bioanal. Chem. 2007; 389:1017-1031. [PubMed: 17668192]

2. Aebersold R, Mann M. Mass spectrometry-based proteomics. Nature. 2003; 422:198-207. [PubMed: 12634793]

3. Thelen JJ, Peck SC. Quantitative proteomics in plants: choices in abundance. Plant Cell. 2007; 19:3339-3346. [PubMed: 18055608]

4. Gygi SP, Rist B, Gerber SA, Turecek F, Gelb MH, Aebersold R. Quantitative analysis of complex protein mixtures using isotope-coded affinity tags. Nat. Biotechnol. 1999; 17:994-999. [PubMed: 10504701]

5. Oda Y, Huang K, Cross FR, Cowburn D, Chait BT. Accurate quantitation of protein expression and site-specific phosphorylation. Proc. Natl. Acad. Sci. USA. 1999; 96:6591-6596. [PubMed: 10359756]

6. Paša-Tolić L, Jensen PK, Anderson GA, Lipton MS, Peden KK, Martinovic S, Tolic N, Bruce JE, Smith RD. High-throughput proteome-wide precision measurements of protein expression using mass spectrometry. J. Am. Chem. Soc. 1999; 121:7949-7950.

7. Ong SE, Mann M. Mass spectrometry-based proteomics turns quantitative. Nat. Chem. Biol. 2005; 1:252-262. [PubMed: 16408053]

8. Yao X, Freas A, Ramirez J, Demirev PA, Fenselau C. Proteolytic ${ }^{18} \mathrm{O}$ labeling for comparative proteomics: model studies with two serotypes of adenovirus. Anal. Chem. 2001; 73:2836-2842. [PubMed: 11467524] 
9. Ross PL, Huang YN, Marchese JN, Williamson B, Parker K, Hattan S, Khainovski N, Pillai S, Dey S, Daniels S, Purkayastha S, Juhasz P, Martin S, Bartlet-Jones M, He F, Jacobson A, Pappin DJ. Multiplexed protein quantitation in Saccharomyces cerevisiae using amine-reactive isobaric tagging reagents. Mol. Cell. Proteomics. 2004; 3:1154-1169. [PubMed: 15385600]

10. Schmidt MW, Houseman A, Ivanov AR, Wolf DA. Comparative proteomic and transcriptomic profiling of the fission yeast Schizosaccharomyces pombe. Mol. Syst. Biol. 2007; 3:79. [PubMed: 17299416]

11. Gerber SA, Rush J, Stemman O, Kirschner MW, Gygi SP. Absolute quantification of proteins and phosphoproteins from cell lysates by tandem MS. Proc. Natl. Acad. Sci. USA. 2003; 100:69406945. [PubMed: 12771378]

12. Old WM, Meyer-Arendt K, Aveline-Wolf L, Pierce KG, Mendoza A, Sevinsky JR, Resing KA, Ahn NG. Comparison of label-free methods for quantifying human proteins by shotgun proteomics. Mol. Cell. Proteomics. 2005; 4:1487-1502. [PubMed: 15979981]

13. America AH, Cordewener JH. Comparative LC-MS: a landscape of peaks and valleys. Proteomics. 2008; 8:731-749. [PubMed: 18297651]

14. Luduena RF. Multiple forms of tubulin: different gene products and covalent modifications. Intl. Rev. Cytol. 1998; 178:207-275.

15. Khodiyar VK, Maltais LJ, Sneddon KM, Smith JR, Shimoyama M, Cabral F, Dumontet C, Dutcher SK, Harvey RJ, Lafanechere L, Murray JM, Nogales E, Piquemal D, Stanchi F, Povey S, Lovering RC. A revised nomenclature for the human and rodent a-tubulin gene family. Genomics. 2007; 90:285-289. [PubMed: 17543498]

16. Verdier-Pinard P, Pasquier E, Xiao H, Burd B, Villard C, Lafitte D, Miller LM, Angeletti RH, Horwitz SB, Braguer D. Tubulin proteomics: towards breaking the code. Anal. Biochem. 2009; 384:197-206. [PubMed: 18840397]

17. Chelius D, Bondarenko PV. Quantitative profiling of proteins in complex mixtures using liquid chromatography and mass spectrometry. J. Proteome Res. 2002; 1:317-323. [PubMed: 12645887]

18. Bondarenko PV, Chelius D, Shaler TA. Identification and relative quantitation of protein mixtures by enzymatic digestion followed by capillary reversed-phase liquid chromatography-tandem mass spectrometry. Anal. Chem. 2002; 74:4741-4749. [PubMed: 12349978]

19. Nogales E, Wolf SG, Downing KH. Structure of the a $\beta$-tubulin dimer by electron crystallography. Nature. 1998; 391:199-203. [PubMed: 9428769]

20. Decottignies A, Grant AM, Nichols JW, de Wet H, McIntosh DB, Goffeau A. ATPase and multidrug transport activities of the overexpressed yeast ABC protein Yor1p. J. Biol. Chem. 1998; 273:12612-12622. [PubMed: 9575223]

21. Gupta ML Jr, Bode CJ, Georg GI, Himes RH. Understanding tubulin-Taxol interactions: mutations that impart Taxol binding to yeast tubulin. Proc. Natl. Acad. Sci. USA. 2003; 100:6394-6397. [PubMed: 12740436]

22. Foland TB, Dentler WL, Suprenant KA, Gupta ML Jr, Himes RH. Paclitaxel-induced microtubule stabilization causes mitotic block and apoptotic-like cell death in a paclitaxel-sensitive strain of Saccharomyces cerevisiae. Yeast. 2005; 22:971-978. [PubMed: 16134117]

23. Bradford MM. A rapid and sensitive method for the quantitation of microgram quantities of protein utilizing the principle of protein-dye binding. Anal. Biochem. 1976; 72:248-254. [PubMed: 942051]

24. Newton CN, DeLuca JG, Himes RH, Miller HP, Jordan MA, Wilson L. Intrinsically slow dynamic instability of HeLa cell microtubules in vitro. J. Biol. Chem. 2002; 277:42456-42462. [PubMed: 12207023]

25. Long GL, Winefordner JD. Limits of detection: a closer look at the IUPAC definition. Anal. Chem. $1983 ; 55: 712 \mathrm{~A}-724 \mathrm{~A}$.

26. Alterman MA, Kornilayev B, Duzhak T, Yakovlev D. Quantitative analysis of cytochrome p450 isozymes by means of unique isozyme-specific tryptic peptides: a proteomic approach. Drug Metab. Dispos. 2005; 33:1399-1407. [PubMed: 15951447]

27. Risinger AL, Jackson EM, Polin LA, Helms GL, LeBoeuf DA, Joe PA, Hopper-Borge E, Luduena RF, Kruh GD, Mooberry SL. The taccalonolides: microtubule stabilizers that circumvent clinically relevant taxane resistance mechanisms. Cancer Res. 2008; 68:8881-8888. [PubMed: 18974132] 
28. Hagman C, Ricke D, Ewert S, Bek S, Falchetto R, Bitsch F. Absolute quantification of monoclonal antibodies in biofluids by liquid chromatography-tandem mass spectrometry. Anal. Chem. 2008; 80:1290-1296. [PubMed: 18217771]

29. Lehmann U, Wienkoop S, Tschoep H, Weckwerth W. If the antibody fails: a mass Western approach. Plant J. 2008; 55:1039-1046. [PubMed: 18485062]

30. Verdier-Pinard P, Wang F, Burd B, Angeletti RH, Horwitz SB, Orr GA. Direct analysis of tubulin expression in cancer cell lines by electrospray ionization mass spectrometry. Biochemistry. 2003; 42:12019-12027. [PubMed: 14556633]

31. Kamath K, Wilson L, Cabral F, Jordan MA. $\beta$ III-Tubulin induces paclitaxel resistance in association with reduced effects on microtubule dynamic instability. J. Biol. Chem. 2005; 280:12902-12907. [PubMed: 15695826]

32. Katsetos CD, Herman MM, Mork SJ. Class III $\beta$-tubulin in human development and cancer. Cell Motil. Cytoskel. 2003; 55:77-96.

33. Pasquier E, Kavallaris M. Microtubules: a dynamic target in cancer therapy. IUBMB Life. 2008; 60:165-170. [PubMed: 18380008]

34. Gan PP, Pasquier E, Kavallaris M. Class III $\beta$-tubulin mediates sensitivity to chemotherapeutic drugs in non-small cell lung cancer. Cancer Res. 2007; 67:9356-9363. [PubMed: 17909044]

35. Seve P, Lai R, Ding K, Winton T, Butts C, Mackey J, Dumontet C, Dabbagh L, Aviel-Ronen S, Seymour L, Whitehead M, Tsao MS, Shepherd FA, Reiman T. Class III $\beta$-tubulin expression and benefit from adjuvant cisplatin/vinorelbine chemotherapy in operable non-small cell lung cancer: analysis of NCIC JBR.10. Clin. Cancer Res. 2007; 13:994-999. [PubMed: 17289895]

36. Hayashi Y, Kuriyama H, Umezu H, Tanaka J, Yoshimasu T, Furukawa T, Tanaka H, Kagamu H, Gejyo F, Yoshizawa H. Class III $\beta$-tubulin expression in tumor cells is correlated with resistance to docetaxel in patients with completely resected non-small-cell lung cancer. Intern. Med. 2009; 48:203-208. [PubMed: 19218769]

37. Seve P, Mackey J, Isaac S, Tredan O, Souquet PJ, Perol M, Lai R, Voloch A, Dumontet C. Class III $\beta$-tubulin expression in tumor cells predicts response and outcome in patients with non-small cell lung cancer receiving paclitaxel. Mol. Cancer Ther. 2005; 4:2001-2007. [PubMed: 16373715]

38. Burkhart CA, Kavallaris M, Band Horwitz s. The role of $\beta$-tubulin isotypes in resistance to antimitotic drugs. Biochim. Biophys. Acta. 2001; 1471:O1-O9. [PubMed: 11342188]

39. Dumontet C, Jordan MA, Lee FF. Ixabepilone: targeting $\beta$ III-tubulin expression in taxane-resistant malignancies. Mol. Cancer Ther. 2009; 8:17-25. [PubMed: 19139109] 

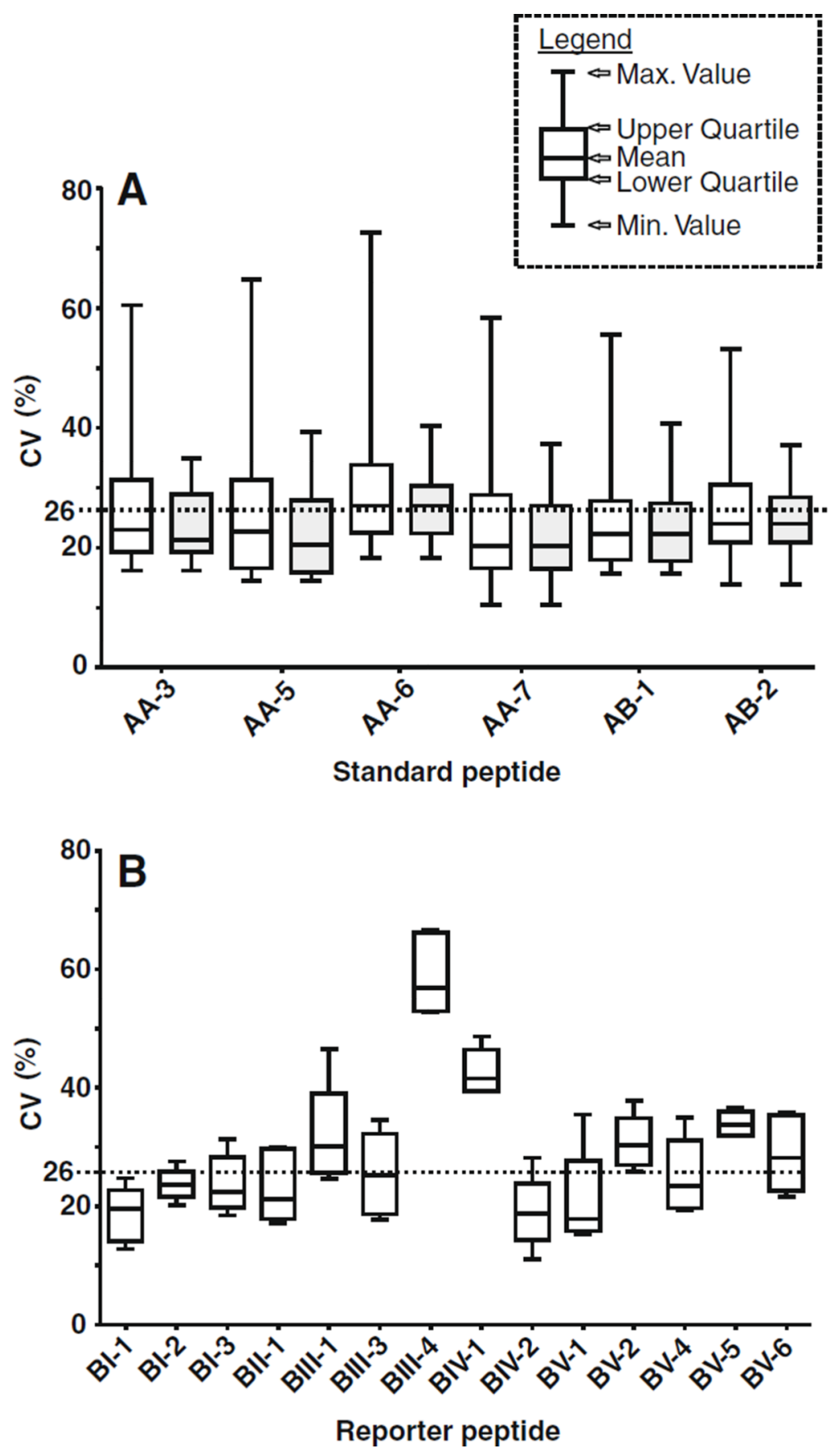

Fig. 1.

(A) Box and whisker plots displaying the distribution of observed abundance ratios of standard peptides from multiple tryptic digests of HeLa tubulin. Unshaded box and whisker plots show the dispersion of the CVs of abundance ratios for every nonredundant combination of potential standard peptides. Shaded box and whisker plots were replotted after omitting data obtained from peptides AA-1, AA-2, and AA-4. The omission reduces both the range (represented by the length of the plot whiskers) and interquartile range (represented by the length of the box). This indicates that the total variance has decreased. Max., maximum; Min., minimum. (B) Box and whisker plots of the CVs of abundance ratios for potential reporter peptides paired with the reliable standard peptides identified in (A). 
Peptides with a median score above the established baseline median CV (26\%) are deemed to be unreliably released by trypsin and not used for analysis. 


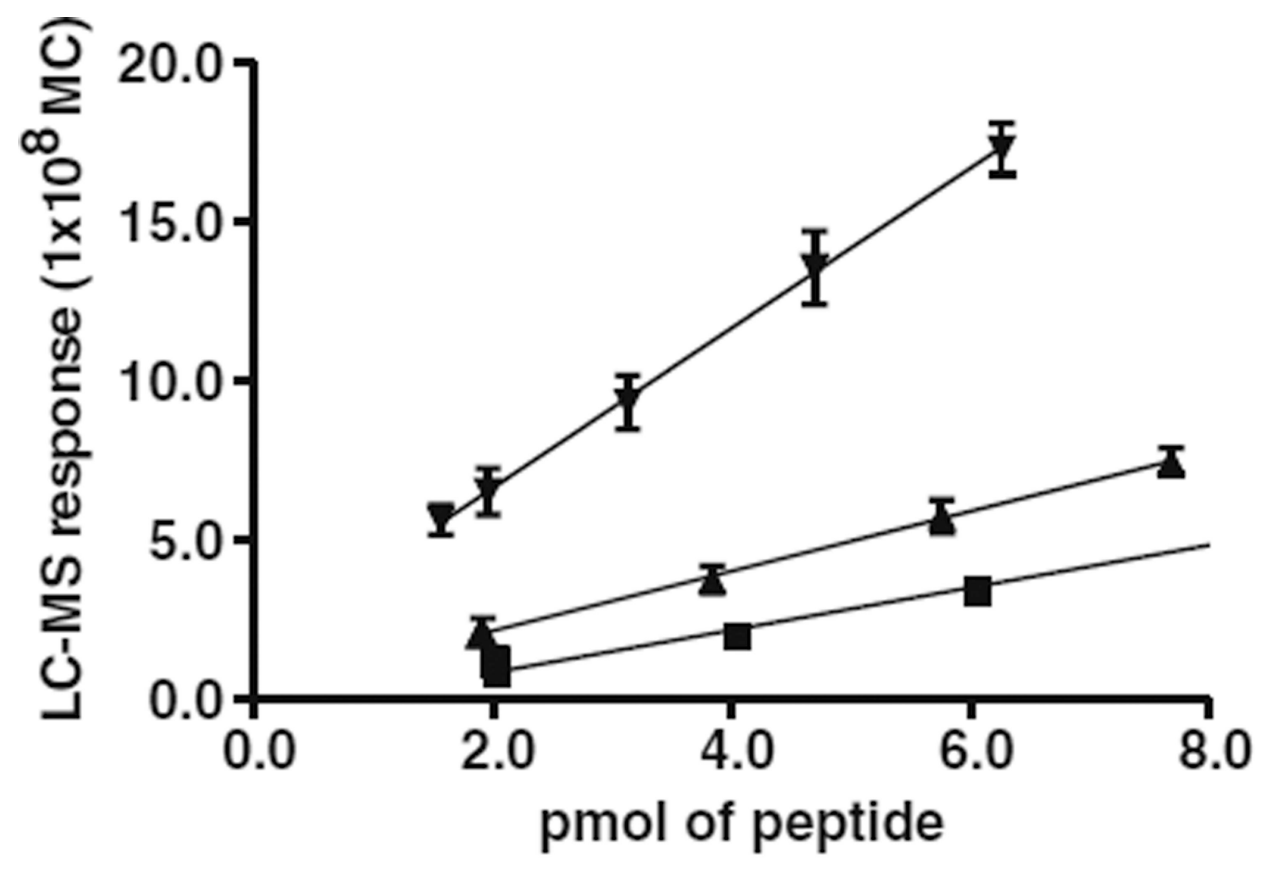

Legend
- AA-3
× $\mathrm{AB}-1$
च $\mathrm{Bl}-1$
- BIII-3

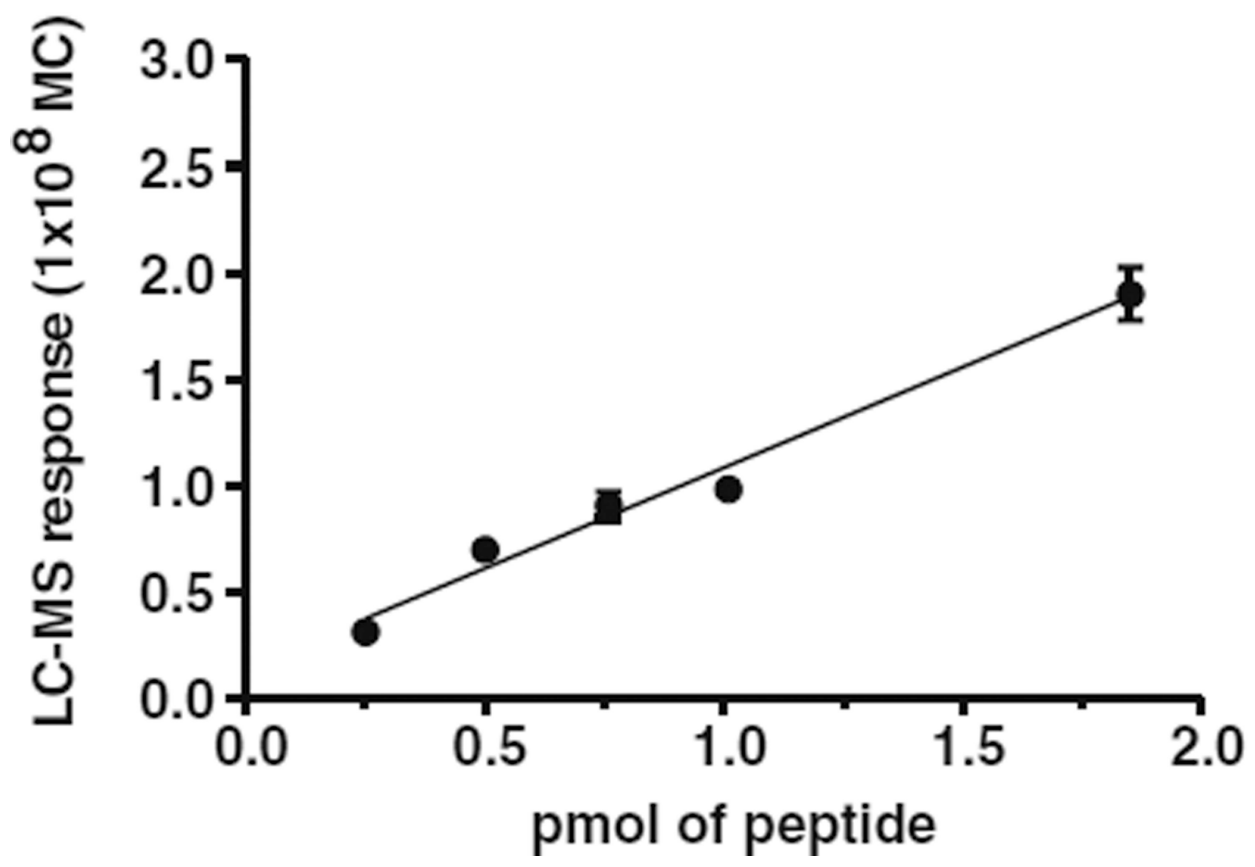

Fig. 2.

Linear regression analysis to determine the LC-MS response factors for select standard and reporter peptides (data given in Table 2). Mean LC-MS signal is defined as the integrated area under the XIC chromatographic peak determined to belong to the peptide. Error bars depict the SD. MC, machine counts. The response factor and $R^{2}$ data were calculated by linear regression analysis using Prism 4.03 software (GraphPad Software, San Diego, CA, USA). 

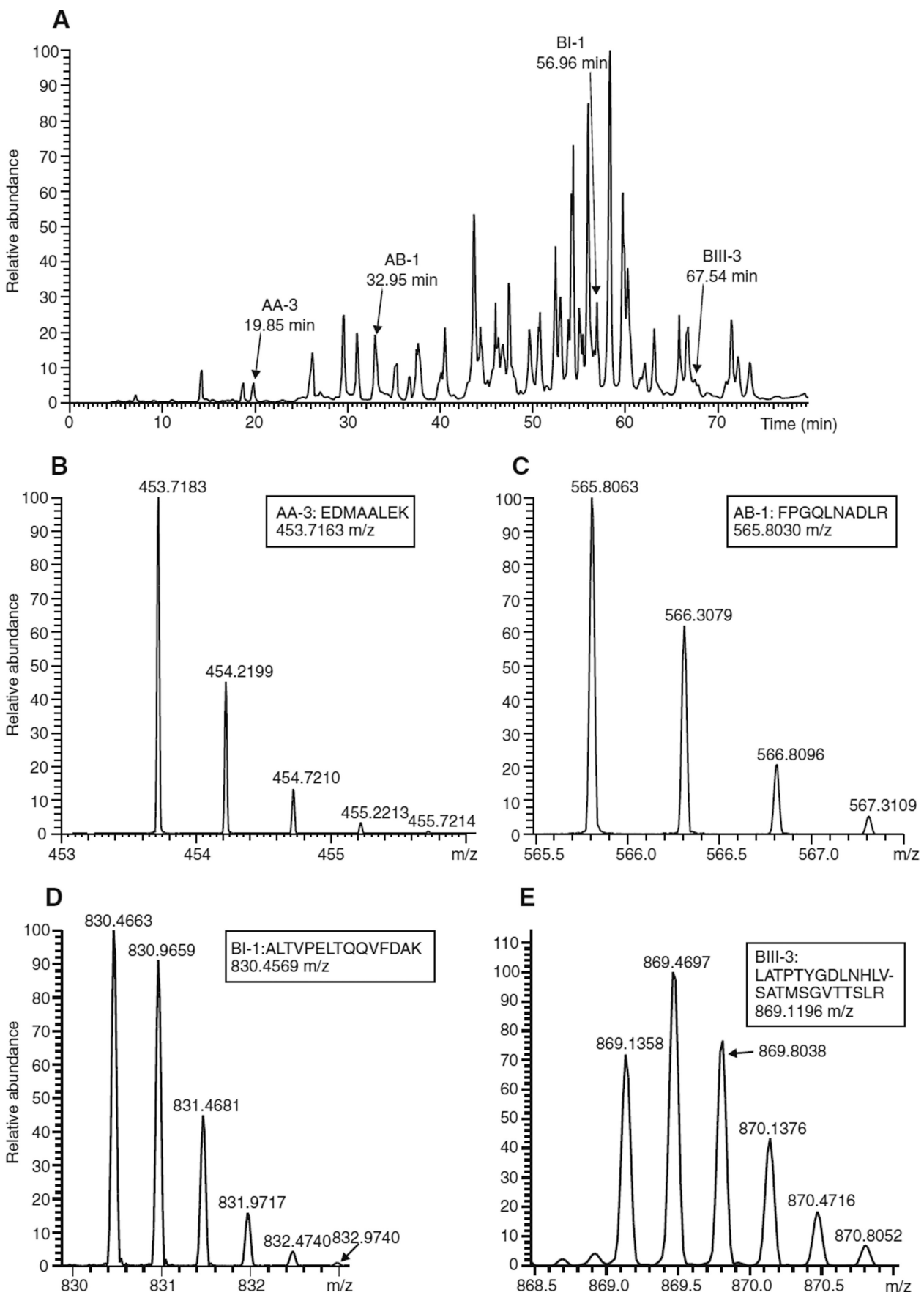

Fig. 3.

Typical chromatographic elution profiles for a tryptic digest of HeLa tubulin. (A) Peaks containing peptides AA-3, AB-1, BI-1, and BIII-3. (B-E) Mass spectra for peptides AA-3 (B), AB-1 (C), BI-1 (D), and BIII-3 (E). 
Table 1

Sequences, origins, charges, and masses of standard and reporter peptide ions detected in this study

\begin{tabular}{|c|c|c|c|}
\hline Code & Sequence & Charge & Mass (Da) \\
\hline \multicolumn{4}{|c|}{ Standard peptides } \\
\hline \multicolumn{4}{|c|}{ All a-tubulin } \\
\hline AA-1 & ${ }_{403}$ AFVHWYVGEGMEEGEFSEAR $_{422}$ & 3 & 777.3555 \\
\hline AA-2 & ${ }_{97}$ EDAANNYAR $_{105}$ & 2 & 512.2284 \\
\hline AA-3 & ${ }_{423}$ EDMAALEK $_{430}$ & 2 & 453.7163 \\
\hline AA-4 & ${ }_{244}$FDGALNVDLTEFQTNLVPYPR $_{264}$ & 3 & 803.7487 \\
\hline AA-5 & ${ }_{216}$ NLDIERPTYTNLNR $_{229}$ & 2 & 859.9463 \\
\hline AA-6 & ${ }_{353}$ VGINYQPPTVVPGGDLAK 370 & 2 & 912.9999 \\
\hline AA-7 & ${ }_{85}$ QLFHPEQLITGK ${ }_{105}$ & 2 & 705.9012 \\
\hline \multicolumn{4}{|c|}{ All $\beta$-tubulin } \\
\hline $\mathrm{AB}-1$ & ${ }_{242}$ FPGQLNADLR $_{251}$ & 2 & 565.8030 \\
\hline $\mathrm{AB}-2$ & ${ }_{253}$ LAVNMVPFPR $_{262}$ & 2 & 572.3210 \\
\hline \multicolumn{4}{|c|}{ Reporter peptides } \\
\hline \multicolumn{4}{|c|}{$\beta I(P 07437)$} \\
\hline BI-1 & ${ }_{283}$ ALTVPELTQQVFDAK $_{297}$ & 2 & 830.4569 \\
\hline BI-2 & ${ }_{20}$ FWEVISDEHGIDPTGTYHGDSDLQLDR $_{46}$ & 3 & 1034.8159 \\
\hline BI-3 & 363 MAVTFIGNSTAIQELFK 379 & 2 & 935.4968 \\
\hline \multicolumn{4}{|c|}{$\beta I I(Q 9 B V A 1)$} \\
\hline BII-1 & ${ }_{47}$ INVYYNEAAGNK $_{58}$ & 2 & 678.3334 \\
\hline \multicolumn{4}{|c|}{$\beta I I I(Q 13509)$} \\
\hline BIII-1 & ${ }_{20} \mathrm{FWEVISDEHGIDPSGNYVGDSDLQLER}_{46}$ & 3 & 1026.4879 \\
\hline BIII-3 & ${ }_{217}$ LATPTYGDLNHLVSATMSGVTTSLR $_{241}$ & 3 & 869.1196 \\
\hline BIII-4 & ${ }_{363}$ MSSTFIGNSTAIQELFK $_{379}$ & 2 & 937.4802 \\
\hline \multicolumn{4}{|c|}{$\beta I V a$ and $\beta I V b$ (P68371 and P04350) } \\
\hline BIVa-1 & ${ }_{363}$ MAATFIGNSTAIQELFK $_{379}$ & 2 & 929.4765 \\
\hline BIVb-1 & ${ }_{47}$ INVYYNEATGGK $_{58}$ & 2 & 664.8292 \\
\hline \multicolumn{4}{|c|}{$\beta V$ (Q9BUF5) } \\
\hline BV-1 & ${ }_{63}$ AALVDLEPGTMDSVR $_{77}$ & 2 & 787.4001 \\
\hline BV-2 & ${ }_{283}$ ALTVPELTQQMFDAR $_{297}$ & 2 & 860.4439 \\
\hline BV-3 & ${ }_{217}$ LTTPTYGDLNHLVSATMSGVTTSLR $_{241}$ & 3 & 879.1298 \\
\hline BV-4 & 363MASTFIGNSTAIQELFK 379 & 2 & 929.4793 \\
\hline BV-5 & ${ }_{78} \mathrm{SGPFGQLFRPNFIFGQTGAGNNWAK}_{103}$ & 3 & 942.8004 \\
\hline BV-6 & ${ }_{20} \mathrm{FWEVISDEHGIDPAGGYVGDSALQLER}_{46}$ & 3 & 987.4786 \\
\hline
\end{tabular}

Note. Peptides are grouped according to their origin; standard peptides are grouped by tubulin family, and reporter peptides are grouped by parent isotype. Peptides in bold type were identified as being reliably released by trypsin. The sequences of the $\beta$-tubulin isotype peptides were obtained using the UniProtKB/Swiss-Prot database (www.uniprot.org). Database accession numbers listed in parentheses. 


\section{Table 2}

Peptide-specific LC-MS response factors given in machine counts per picomole of peptide in each injection, as calculated by linear regression analysis

\begin{tabular}{|lrl|}
\hline Synthetic peptide & Response factor $\left.\mathbf{( M C / p m o l} \times \mathbf{1 0}^{\mathbf{7}}\right)$ & $\boldsymbol{R}^{\mathbf{2}}$ value \\
\hline AA-3 & 6.66 & 0.9459 \\
AB-1 & 9.38 & 0.9676 \\
BI-1 & 25.14 & 0.9702 \\
BIII-3 & 9.53 & 0.9213 \\
\hline
\end{tabular}

Note. MC, machine counts. 


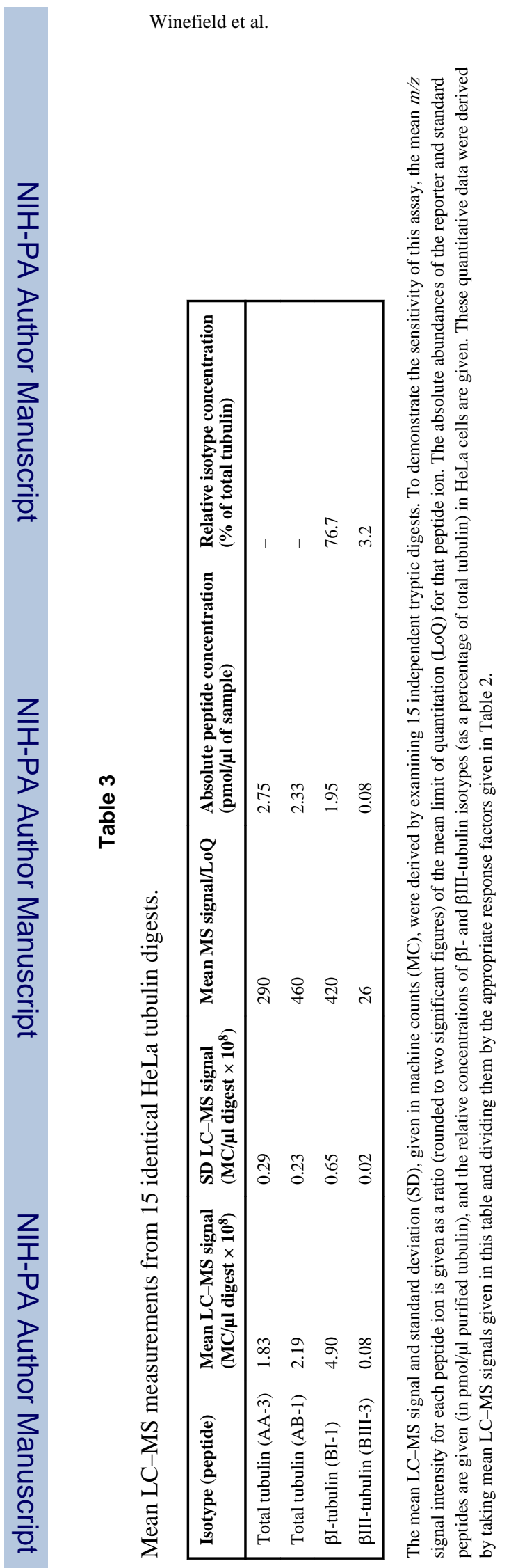

Anal Biochem. Author manuscript; available in PMC 2013 July 15. 